\title{
Sustainable regional development through the use of photovoltaic (PV) systems. The case of the Thessaly region
}

\author{
Roido Mitoula*, Konstadinos Abeliotis, Malvina Vamvakari, Athina Gratsani \\ ${ }^{1}$ Harokopio University, Athens, Greece \\ *Corresponding author. Tel: +30 2109549213, Fax: +30 2109577050, E-mail:mitoula@hua.gr
}

\begin{abstract}
The purpose of this study is the contribution of photovoltaic systems to the Sustainable Development of the region of Thessaly in Greece. The aim is to explore both the potential for further installation of PV systems in the region and to record the opinions, knowledge and attitudes of residents about them. To document the theoretical data was carried out fieldwork using questionnaires given to a sample of 200 residents of the region of Thessaly. The work attempts to clarify the term "Sustainable Development" and what are the factors that contribute to it. The advantages and disadvantages of PV systems and the European policy that is followed in Greece for them, are recorded. The work focuses on solar rooftops and special attention is given to the advantages and disadvantages of solar roofs. The search area is studied and the general characteristics are given. The research, the results of statistical analysis and the $\mathrm{X}^{2}$ test for independence are described. In this way, we are given the possibility to approach the degree to which citizens are informed and sensitized on the issues of photovoltaics. In the last part of the study the results of statistical analysis are commented, the conclusions are recorded and proposals are formulated to improve the current situation and further spread and use of photovoltaic parks and solar roofs in the region of Thessaly.
\end{abstract}

Keywords: Sustainable Regional Development, Photovoltaic Systems Renewable energy.

\section{Introduction}

Nowadays, it has become acceptable that sustainable development is directly linked to energy development. The use and evolution of renewable energy can contribute to the sustainable development of a place, because this will mean environmental protection, and security for the financial resources for this place. (Mitoula, 2006)

Regarding photovoltaic systems, the photovoltaic parks made today at a regional level, produce electricity channeled through the Public Power Corporation (PPC) for the electrification of areas. (www.photovoltaicscom.gr) The same occurs with the installation of PV on the roofs of houses (so-called solar roofs). The advantages of such a practice are many, since firstly, the citizen produces his own electricity for the home and secondly, a profit because it is connected to the electricity network and the "excess" power is sold to it. In this way achieve faster depreciation of the cost of installation. (www.atlantisresearch.gr) (www.helapco.gr), (www.pv-home.gr)

The purpose of this study is the contribution of photovoltaic systems to the Sustainable Development of the region of Thessaly in Greece. The aim of this study is to explore both the potential for further installation of PV systems in the region and to record the opinions, knowledge and attitudes of residents about them. To document the theoretical data was carried out fieldwork using questionnaires given to a sample of 200 residents of the region of Thessaly. The work focus on solar rooftops.

In the last part of the study the results of statistical analysis are commented, the conclusions are recorded and proposals are formulated to improve the current situation and further spread and use of photovoltaic parks and solar roofs in the region of Thessaly. 


\section{Case Study: The region of Thessaly}

The region of Thessaly is the central - eastern part of mainland Greece. It consists of the prefectures of Karditsa, Larissa, Magnesia and Trikala and occupies a total area of 14,036 km $(10.6 \%$ of the total area of the country). (www.thessalia.gov.gr) (Sivignon, 1992) (www.el.wikipedia.org)

In the region of Thessaly operates $19 \%$ of photovoltaic power plants in Greece. The greatest contribution of Thessaly in energy through photovoltaic systems for large power stations, from 150 to $2000 \mathrm{KWp}$, sector which occupies $31 \%$ of national production. $9 \%$ contribute to a small group to $20 \mathrm{~K} \mathrm{Wp}$ and $14 \%$ in average power of $150 \mathrm{~K} \mathrm{Wp}$. Then data on the 4 prefectures of Thessaly are recorded.

In the prefecture of Magnesia, power stations are located, of which 14\% of Thessaly contribution to the national average production of energy is produced. (www.anaptixiakianamth.gr)

The first photovoltaic park double-axis, power $94,5 \mathrm{Kw}$, (6 acres) was created in Stefanovikio of Magnesia in 2009 a nd its operation involves several elements of originality, since the construction is based on a tracking system of the sun (tracker double -axis), thanks to moving rather than stable panels follow the sun, ensuring maximum efficiency. (www.wordpress.com, www.qualitynet.gr). At the same time, authorized another photovoltaic power station same power (2MWp), adjacent to the operating station Industrial Area of Volos.

In the field of solar roofs, the Social Law Center South Pagason of Municipal Agency for Health and Social Affairs of the Municipality of Volos equipped with an integrated system for producing electricity from the sun. The PV panels are composed, produced more than 2.600 KWH per year, offsetting 2.3 tonnes of $\mathrm{CO} 2$ emissions in the same period. The PV system that was installed in front of this building is the first building unit of a municipal building in Greece and the PV modules are specially designed for buildings. (www.aleo-solar.gr) This system is innovative and the aim of Volos is the progressive intervention on e xisting buildings, contributing to environmental protection and energy security for the city. Having such a slogan "Volos-Green Town", the Municipal Authority has been gradually implementing an ambitious program to become the capital of Magnesia benchmark and a model "Green City".

The prefecture of Karditsa, has large areas of high sunshine, a favorable ground for development of this technology, which supports local development. As priority areas for siting installation of exploitation of solar energy are the areas that are barren or are not high productivity and preferably invisible from crowded places, and with opportunities of connectivity to the Network or System. (www.minenv.gr)

Example of installation of PV parks in the prefecture of Karditsa is in the municipality of Campos, where $5 \mathrm{PV}$ parks were constructed, which produce $20 \mathrm{KW} / \mathrm{h}$ each. The funding was made by the Operational Programme "Competitiveness" of the Ministry of Development (45\% subsidy from Ministry of Development and 55\% own contribution). (www.oikosocial.gr) The project makes the municipality electrician producer. The benefits from the operation of this park are numerous and significant for the local community and the wider region. In 2008 e stablished the "Energy Company of municipality of Campos". The local company that took over the project, pledged that $50 \%$ of profits will invested in environmental projects and the remaining or rest of $50 \%$ in activities of cultural, sporting and 
environmental sector, namely development projects for the benefit of the municipality. (www.karditsanews.gr) Also, 2.5 acres used for the installation of PV is like to have created 200 acres of forest. This is because many would be needed to absorb 280 tones of CO2, the release of which prevent the PV. (www.oikosocial.gr)

Also in Artesiano of Karditsa two units of $100 \mathrm{KWp}$ are built in neighboring areas of PV panels of high efficiency, with rated power $100 \mathrm{KWp}$ each. (Www.aleo-solar.gr)

Under construction is PV station in the Industrial Area of Karditsa with power 1MW.

In addition has given a license installation of a power station by PV power systems $0,84 \mathrm{MW}$, in place of the industrial area of Karditsa, Palama Municipality of Karditsa (www.thessaliaespa.gr/Files/espa_episimi.pdf)

Regarding the prefecture of Larissa, in recent years contributes significantly to generating/producing electricity using not only PV parks and solar roofs.

In the municipality Kranona installed PV park, thanks to the special bases of support, following the sun in two directions (two-axles trackers). This provides $40 \%$ more power than conventional - stable installations. Already by $2 / 4 / 2009$ have been saved $1.616,54 \mathrm{~kg} \mathrm{CO}_{2}$ emissions from the PV station rated power of $19.80 \mathrm{~kW}$, which came into full production mode on 13/3/2008. The project was funded under the CSF by the "Competitiveness" of the Ministry of Development, at 55\%. (www.greenproject.gr)

Also, in the municipality Polydamanta was authorized in $2009 \mathrm{~b}$ y the Ministry of Development and the Region of Thessaly, the transmission of energy production license and, installation license of PV station, power 9,99 MW.

In February 2010, in place Kritiri of the municipality Farsala of Larissa, was issued permit installation of PV power station, power 1.998 MWp.

Finally, based on the same article, was issued another permit installation of PV power station, power $4.996 \mathrm{M} \mathrm{Wp}$, in the municipality Narthakiou of Larissa. (www.photovoltaics.com.gr/solar-panel-pv-3.html)

As for the prefecture of Trikala, there is a rapid increase in installed PV systems.

Specifically, the Energy Regulatory Authority (RAE) approved the installation of PV systems with total power 95,04 KWp on the roof of the Technical Vocational High School of the city. This project covers not only the electricity needs of the school but the excess is sold to $\triangle \mathrm{EH}$. The choice of school was for learning and energy purposes. (www.news.trikki.gr)

Also, in $2008 \mathrm{c}$ ompleted the installation of PV power system with power $99.30 \mathrm{KWp}$ in Vasiliki of Trikala. Using the single-axis moving bases, frames are always oriented to the sun by increasing production by $32 \%$. The whole system is supported by a metal circular track of 12 meters in diameter, and thus the suncarrier oriented to the sun every 10 minutes.

The first photovoltaic station in Trikala of "small class" (up to $20 \mathrm{kWp}$ ), built in 2008 in the municipality Paleokastro. (www.aleo-solar.gr) 
In Pigi of Trikala a new photovoltaic park of $19,98 \mathrm{~kW}$ rated power is installed and the connection to the electricity network was held on August 12, 2009.

Also, in the prefecture of Trikala installed PV park on a flat roof of industrial building crafts an extent of 1500 square meters, rated power $19,80 \mathrm{~kW}$. This is the first PV system in Greece installed in the roof using sun tracking system (tracker). Due to the limited installation space and to avoid shadows, preferred to use single-axis tracker, which delivers increased production compared to systems of stable bases (approximately $30-35 \%$ ).

In 2009, completed another PV park rated power 19,98 kW in Faneromeni of Trikala. The project was funded under the third CSF by the program "Competitiveness" of the Ministry of Development, at 55\%. (www.greenproject.gr)

The Municipality Ichalias of Trikala converted in solar center, where completed the installation of two more PV parks of $19,80 \mathrm{~kW}$ each, reaching a total of 4 parks in the area.

In 2010, another permit to construct plants producing electricity from PV systems was issued, with a power of $1,006 \mathrm{MW}$, in the municipality of Paliokastrou in Trikala.

\section{Research}

In the investigation of these issues, in region of Thessaly, a fieldwork was carried out during the period between February and April 2010. 280 completed questionnaires shared, while 200 of those were returned, of which 60 relate to people of Volos, 40 of Karditsa, 60 of Larissa, and 40 of Trikala (total population $=317105$ residents). The number of questionnaires was proportional to the population of each district. Completion of the questionnaire was anonymous, while the sample was selected using the simple random sampling and attempted to cover all the scales of ages and educational levels. After the completion of questionnaires, were processed, followed by checking their validity, the coding of variables and their introduction in the statistical program Statgraphics. Using the statistical program Statgraphics found the percentages. The Excel has the ability to make charts of the percentages of the respective responses of the respondents. Of the 200 pe ople, $46 \%$ are men and $54 \%$ are women. The majority of respondents are aged 20-29, the rest ranging from 30-59 years old and only $3 \%$ are aged 60 or over, which consists of pensioners. The education level of respondents varied, with $52 \%$ ranging from $15.000 €$ to $30.000 €, 12.5 \%$ have an annual household income $<15.000 €, 31 \%$ from $30.000 €$ to $45.000 €$, and $4.5 \%$ of respondents with more than $45.000 €$. One very important factor that could influence the views of respondents are professional jobs where just over half the respondents, $51.5 \%$ appears to be private and civil servants, $11.5 \%$ self-employed, the $20.5 \%$ students, $9 \%$ are employed in households, $4.5 \%$ were unemployed and $3 \%$ retired.

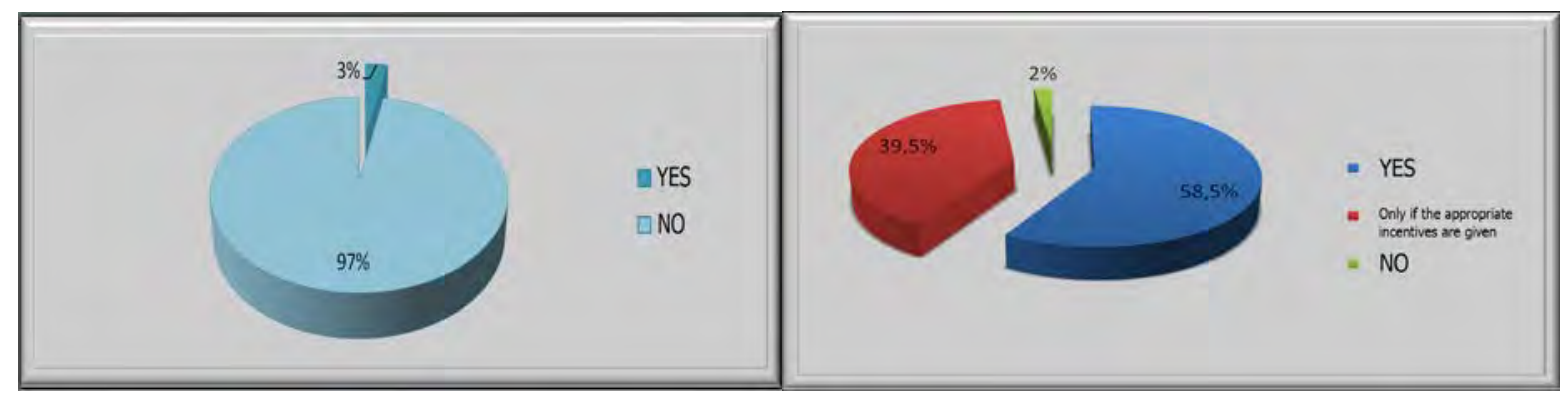

Fig. 1. Have you ever use PV?

Fig. 2. Are you willing to help in reducing energy consumption by using solar energy through PV? 


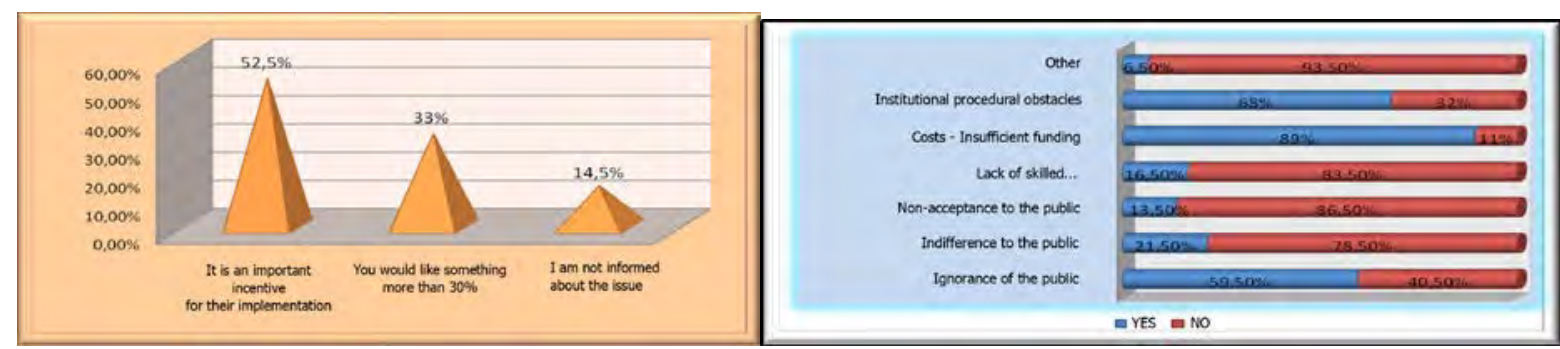

Fig. 3. What about the subsidy by the E.U. for Fig. 4. Obstacles for the use of PV. the use of $P V$ ?

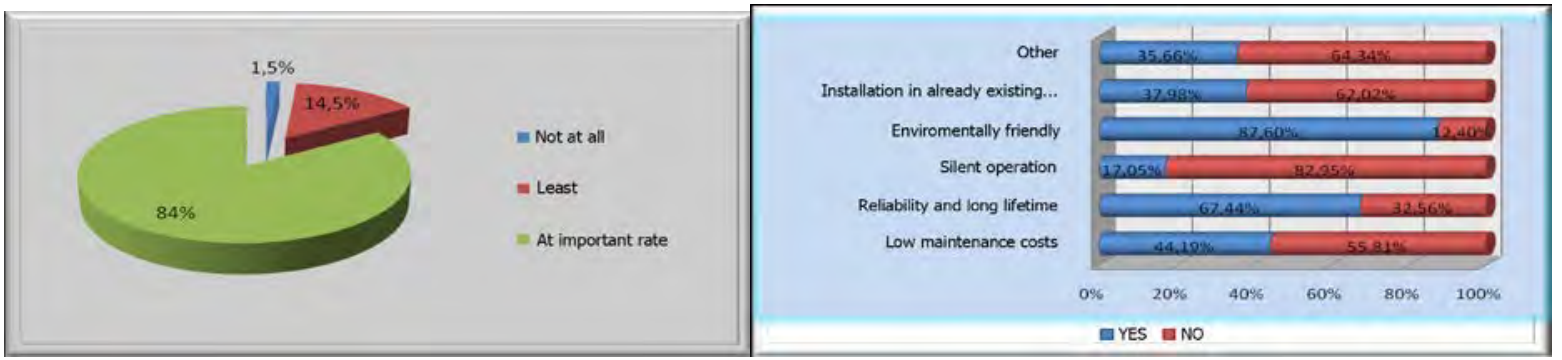

Fig. 5. How PV contribute the Sustainable Development?

Fig. 6. Would you install PV on your rooftops?

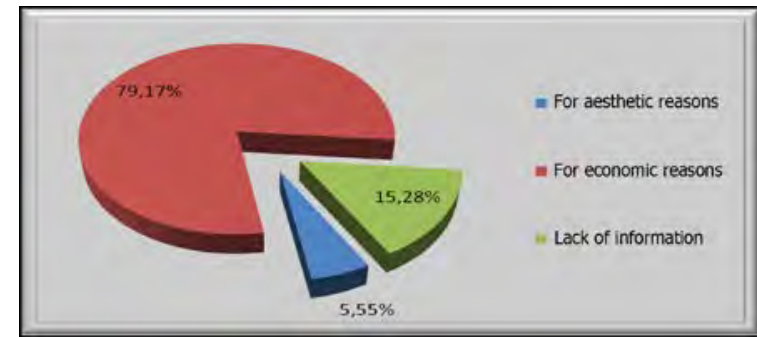

Fig. 7. The others who do not agree with the installation of $P V$ on roofs.

To extract the best conclusion was necessary to examine whether the realization of an event influences another event. To test the degree of dependence between two qualitative variables the $\mathrm{X}^{2}$ test is used. The $\mathrm{X}^{2}$ test of independence is a method that allows us to determine whether two variables are dependent.

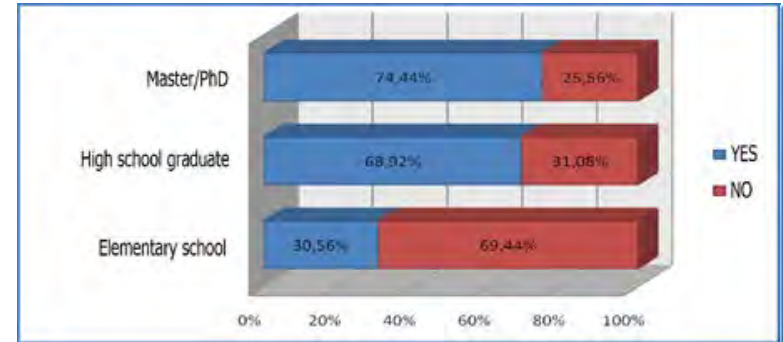

Fig. 8. Correlation of the variables "educational level" and "install PV on roofs"

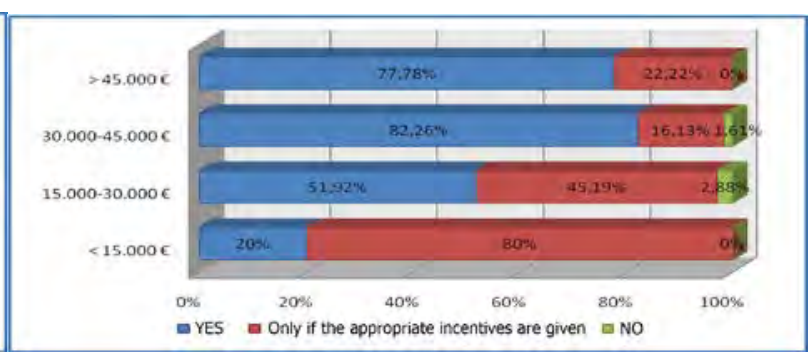

Fig. 9. "annual family income" and "help to reduce energy consumption by using $P V$ 


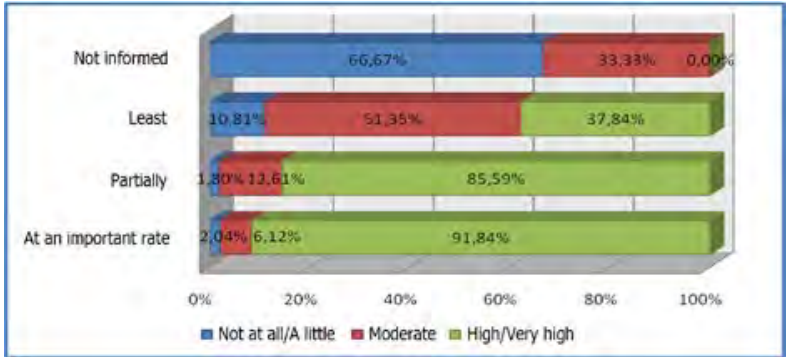

Fig. 10. "information" and "necessity of the installation of $P V$ in the region of Thessaly"

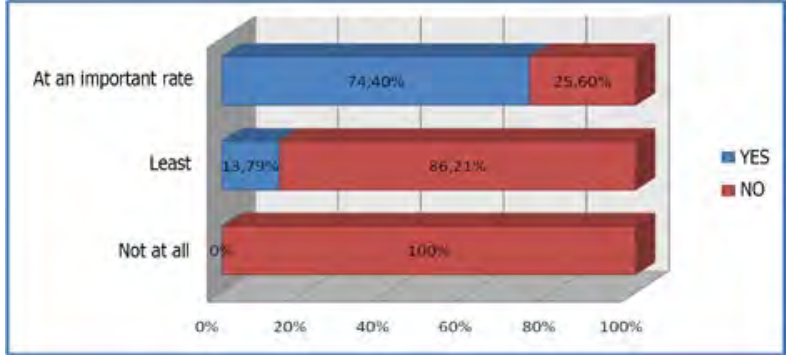

Fig. 11. The intensive use of $P V$ contributed significantly to enhancing sustainable development in the region of Thessaly, the majority agree with the installation of $P V$ on their roofs

\section{Discussion}

The above survey shows that residents are aware of issues of environmental protection. Furthermore, they are interested in the development of their country and are willing to accept the further use of photovoltaic systems.

97\% of the sample have not used PV but are willing to shift to the use of solar energy through photovoltaic systems instead of conventional energy (polluting fuels). On the issue of EU subsidies for application of PV systems exist 2 views exist: in the one hand a subsidy is an important incentive, while on the other hand, a large proportion of the sample considers that the subsidy amount is small compared with the obstacles facing such an action. Also, in the opinion of the sample, there are major institutional problems (bureaucracy, etc.) problems of cost (design, purchase and installation). Therefore, the willingness, determination and environmental consciousness exists, but others are the factors that contribute to the further development of PV systems.

The survey showed that people propose funding from the government, further and better information about the account issues from media and press. Generally, regular information and awareness of public is demonstrated by research that leads to change human behavior, without neglecting the education/training from an early age.

Arguing that the PV systems contribute to sustainable development of the Region of Thessaly, the respondents indicate that the growth sectors that will most affected by the widespread application of PV as a renewable energy, is initially the economy. This is because new jobs, liquidity in the region and independence as a point of fueling are created. The impact on the environment will also be positive, due to reduced emissions, the friendly operation of PV on it, and the recyclability of construction materials. At the same time, the employment of many people working in research on environmentally friendly technology is enhanced.

The subject of the installation of PV on roofs (so-called solar roofs), is a very important part of research because from the results that carried out, is concluded that the largest percentage of respondents who would make installation, are based on the following reasons: they are environmentally friendly, provide reliability and long life, and of course the maintenance cost is very low. Note however that the reason why they would not install, is more economical.

Then, indicated that, the better the educational level of each respondent is, the greater and the eagerness to help in reducing energy consumption by using solar. This happens because the level of education means more knowledge, not just for one particular sector, but general as 
long-term benefits, impacts, even in conjunction with other sectors. Moreover, in the case of solar roofs, it is concluded that the higher the educational level is, the higher the percentage of respondents are agreeing with the installation of PV on rooftops. It seems therefore, that this feature reduces the hesitation, financial or otherwise, for such an installation.

Another factor that contributes to the willingness of respondents to install PV is the annual family income, even if it undermines the protection of the environment. The higher the annual household income is, the percentage of people who are interested to help in the effort of reducing energy consumption by using PV increases. In addition the needs of one person to the other differ, also differ in their beliefs, willingness and interests that are directly affected by income. Moreover, employment, which is linked to income, is also a factor that influences the views of persons. The above observed from the fact that the majority of workers support the view that the subsidy that is given by the EU for the application of PV is an important incentive, unlike the pensioners, the unemployed and those employed as household who believe that although is a motive, they would like more subsidy. Implicitly/ Indirectly, then is confirmed that the higher the level of awareness of energy saving issues and renewable energy is, the positive attitude of respondents towards the necessity of installation of PV in the region of Thessaly increases, because of long-term benefits that they offer.

Therefore, for the installation of photovoltaic park in the region, openness and condescension increaese as increasing the willingness to the effort of reducing energy consumption by using solar energy through PV instead of polluting fossil fuels for electricity in the region. Finally, it turns out that sustainable development makes/gives a 'functionality', supports the invulnerable and endlessly point of this development over the years, reinforce local and regional development in conjunction with the RES, because the higher the percentage of respondents who believe that the intensive use of PV contributes to reinforcement of sustainable development is, the possibility of installation of PV on the roofs increases.

\section{Conclusions}

The region of Thessaly is largely dependent on f ossil fuel, but on the potential use of photovoltaic systems is satisfactory level. The above study also demonstrated the positive attitude of the residents of Thessaly toward this type of systems.

In conclusion, the use of photovoltaic systems is significantly close to the new perspectives of balanced development, which seeks to ensure environmental quality, economic development and improving social cohesion. Also emphasized that the region of Thessaly is the second in Greece in the frequency of using photovoltaics for electricity production, resulting in energy to contribute significantly to sustainable regional development.

\section{References}

[1] Mitoula R., "Sustainable Regional Development in the European Union and the Greek Reconstruction of Urban Environment, ed Stamoulis, Athens, 2006, p.27-30, 76

[2] www.photovoltaics.com.gr/solar-panel-pv-3.html

[3] www.atlantisresearch.gr/files/ap5820_ENHMEROTIKO_148.pdf

[4] www.helapco.gr/library/23_7_09/Solar_Roofs_Q\&A_d.pdf

[5] www.pv-home.gr/

[6] www.thessalia.gov.gr/contents.asp?id=167 
[7] Sivignon M. (1992), "Thessaly, a region of geographic analysis', Educational Institute of Agricultural Bank Translation: Julie Anastopoulou, Athens, p. 69-70

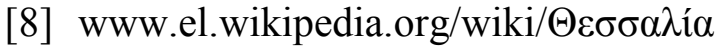

[9] www.anaptixiaki-

namth.gr/index.php?option $=$ com_content $\&$ task $=$ view $\&$ id $=5260 \&$ Itemid $=65$

[10] www.aleo-solar.gr/index.php?view $=$ item \&catid=207\%3Agreece $\& i d=128 \% 3$ A2010-0127-10-05-07\&option $=$ com aleoreferenzen\&Itemid $=689$

[11]www.minenv.gr/4/42/00/sxedio.kya.ape.pdf

[12] www.oikosocial.gr/index.php?option $=$ com_content\&view $=$ article\&id $=221: 2010-01-08$ 14-35-40\&catid $=43: 2009-10-08-07-38-59$ \& Itemid $=81$

[13] www.karditsanews.gr

[14]www.thessalia-espa.gr/Files/espa_episimi.pdf

[15]www.greenproject.gr/a8.html

[16]www.news.trikki.gr 